\title{
Gastos de campaña en 2012: la equidad rota. Discutible constitucionalidad de la elección presidencial
}

\section{Eduardo R. Huchim*}

\section{Sumario:}

I. Introducción

II. La invalidez por violación de principios constitucionales

III. Los gastos excesivos de campaña violan la equidad y pueden generar la invalidez

IV. La demanda de la coalición Movimiento Progresista

V. Informe del IFE y argumentos de la coalición tercera interesada

VI. Valoración de la Sala Superior: los tiempos de la fiscalización

VII. ¿Es posible cancelar el registro por rebasar los topes de campaña?

VIII. La rechazada "excitativa de justicia" del Movimiento Progresista

IX. Conclusiones

X. Propuestas

* Periodista, escritor y ex consejero del Consejo General del IEDF. Colabora regularmente en el diario Reforma. 


\section{Introducción}

La presencia del dinero en la política mexicana ha sido y es muchas cosas a la vez: necesidad, exceso, inequidad, litigio, corrupción, entre otras. También desmesura, si recordamos que los partidos políticos se han permitido fijar su financiamiento no sólo en la ley sino incluso en la Constitución misma.

Después de que durante decenios el dinero público fluyó sólo a un partido político, el Revolucionario Institucional, a partir de 1977 comenzó a llegar tímidamente a todos los partidos y, en particular desde 1996, el flujo fue creciente y, para muchos, excesivo. Así, un dirigente partidario, Felipe Calderón Hinojosa, del Partido Acción Nacional, protagonizó en 1997 el episodio insólito de reintegrar a las arcas públicas una parte del financiamiento que le correspondía a su partido, por considerar que era demasiado, una actitud que no prevaleció, pues muy pronto el PAN comenzó a aceptar todos los dineros que le correspondían conforme a la ley.

El financiamiento público a los partidos fue creciendo con los años y hoy la timidez inicial se ha convertido en exceso. Conforme al esquema de financiamiento determinado en 2007, los partidos recibieron en 2012, en conjunto y por tres conceptos (gasto ordinario, campaña y actividades específicas), 5142 millones de pesos que se distribuyeron según el número de votos obtenido en los comicios de 2009. El partido con mayores recursos asignados fue el PRI, con 1644 millones de pesos, en tanto que Movimiento Ciudadano (antes Convergencia) resultó el pariente pobre, con 315 millones. En tanto, los otros dos partidos más votados, PAN y PRD, obtuvieron 1300 y 690 millones de pesos, respectivamente.

Esa distribución se ajusta a lo dispuesto por la ley, ${ }^{1}$ pero es obvio que la equidad no resulta bien servida. Parece sensato que se privilegie

1 Con la reforma electoral de 2007, la fórmula para calcular el financiamiento partidario cambió y el artículo que la recoge, el 41, base segunda, inciso $a$, de la Constitución, la establece así:

El financiamiento público para el sostenimiento de sus actividades ordinarias permanentes se fijará anualmente, multiplicando el número total de ciudadanos inscritos en el padrón electoral por el sesenta y cinco por ciento del salario mínimo diario vigente para el Distrito Federal. El treinta por ciento de la cantidad que resulte de acuerdo a lo señalado anteriormente, se distribuirá entre los partidos políticos en forma igualitaria y el 
con financiamiento la obtención del mayor número de sufragios, pero ya no parece tan sensato que las diferencias sean abismales. Sobre este punto he venido planteando la conveniencia de reformar las reglas de la asignación, en la forma que detallo en el apartado de propuestas.

De cara a las campañas electorales y a las ventajas que se derivan de disponer de mayor financiamiento, el legislador creó la figura del tope de gastos de campaña, es decir un límite al que se deben sujetar todos los candidatos y partidos contendientes, si bien resulta difícil encontrar una elección importante, sobre todo en los casos de los ejecutivos federal y estatales, en que tales límites se respeten.

No es raro que tal cosa ocurra, porque los contendientes no han hallado incentivos para respetar esos topes. Al contrario, tienen estímulos para sobrepasarlos, y por esa vía se actualiza lo que la OEA y el PNUD han apuntado: "Los recursos disponibles para los partidos y candidatos pueden ser la fuente de una clara ventaja sobre competidores electorales". ${ }^{2}$

El principal de esos incentivos perversos es que los tribunales electorales, tanto federal como estatales, casi nunca encuentran determinancia suficiente para invalidar comicios a causa de exceder los límites de gastos, aun cuando el exceso esté legalmente considerado como causal de nulidad, y por tanto, la victoria lograda en las urnas prevalece aun cuando haya sido obtenida ilegalmente. De ese modo, si bien frecuentemente se fijan sanciones económicas, la relativa impunidad es una eficiente estimulación para el irrespeto a los límites económicos a las campañas.

En este marco, era previsible que la Sala Superior del Tribunal Electoral del Poder Judicial de la Federación, como lo ha hecho una y otra vez respecto de comicios estatales, desestimara los argumentos, pruebas e indicios que presentó la coalición Movimiento Progresista (PRD, PT y MC) que postuló a Andrés Manuel López Obrador, respecto de lo que consideró un rebase del tope de gastos de campaña por la coalición Compromiso por México (PRI y PVEM) que postuló a Enrique Peña Nieto.

setenta por ciento restante de acuerdo con el porcentaje de votos que hubieren obtenido en la elección de diputados inmediata anterior.

2 Programa de las Naciones Unidas para el Desarrollo, Secretaría General de la Organización de los Estados Americanos, Nuestra democracia, México, FCE, 2010, p. 118. 
En el presente texto se examinará el juicio de inconformidad SUPJIN-359/2012, que demandaba la nulidad de la elección presidencial. El análisis se centrará en lo concerniente a los gastos de campaña del candidato priista.

\section{La invalidez por violación de principios constitucionales}

Antes de entrar a la valoración que realizó el tribunal, conviene detenerse en algunas de las consideraciones preliminares que formuló la Sala Superior en el considerando tercero, bajo el rubro "Consideraciones generales sobre la pretensión de nulidad de la elección presidencial por violación a los principios constitucionales", en cuya parte inicial se dice:

Esta Sala Superior considera relevante, antes de entrar al estudio de los temas planteados por la coalición Movimiento Progresista, pronunciarse sobre su pretensión de nulidad de la elección por la violación a los principios constitucionales que rigen toda elección democrática ${ }^{3}$ y precisar algunos elementos básicos relacionados con su competencia en el marco del conjunto del sistema jurídico vigente.

$\mathrm{Al}$ respecto, esta Sala Superior considera que, en ejercicio de sus atribuciones constitucionales y legales, así como en atención a los derechos y principios fundamentales previstos en los tratados internacionales de derechos humanos que derivan en obligaciones concretas de respeto y garantía de los mismos, puede válidamente declarar la invalidez o nulidad de la elección de Presidente de los Estados Unidos Mexicanos por conculcación de determinados principios constitucionales o por la vulneración de ciertos valores fundamentales e indispensables para considerar una elección como libre, auténtica y democrática, siempre que se encuentren plenamente acreditas (sic) irregularidades graves, generalizadas o sistemáticas y resulten determinantes para el resultado de la elección.

3 Véase la tesis X/2001, Elecciones. Principios constitucionales y legales Que SE DEBEN OBSERVAR PARA QUE CUALQUIER TIPO DE ELECCIÓN SEA CONSIDERADA VÁLIDA, Compilación 1997-2012. Jurisprudencia y tesis en materia electoral. Tesis, México, TEPJFvol. 2, t. I, pp. 1075-1077. 
Lo anterior deriva, no sólo de las facultades específicas previstas en la legislación electoral, sino particularmente de los principios y valores constitucionales y derechos fundamentales previstos tanto en la Constitución Política de los Estados Unidos Mexicanos como en los tratados internacionales de derechos humanos que reconocen los derechos políticos de votar y ser votado en elecciones periódicas auténticas, realizadas por sufragio universal e igual y por voto secreto que garantice la libre expresión de la voluntad de los electores.

Este criterio del TEPJF es relevante a causa de la disposición constitucional contenida en el artículo $99,{ }^{4}$ en el sentido de que este tribunal sólo puede declarar la nulidad de una elección por "las causales que expresamente se establezcan en las leyes", pero no se prevé qué pasa cuando existen violaciones graves a la Constitución y no están previstas en la ley como causales de nulidad. La Sala Superior recordó que en la sentencia SUP-JRC-165/2008, del 26 de diciembre de 2008, "se dio cabida al estudio de irregularidades que expresamente no están reguladas en la ley como conductas que acarrean la nulidad de la elección pero que pueden violar los principios constitucionales previstos en la Ley Fundamental" y llegó a la conclusión de que el TEPJF puede declarar la invalidez de la elección presidencial. En el mismo apartado de la sentencia motivo del presente análisis se plantearon también estos importantes criterios:

a) Las salas del TEPJF son "autoridades de jurisdicción constitucional" a las cuales se les encomienda el sistema de control de constitucionalidad y legalidad y, por tanto, pueden analizar si

4 El artículo 99 de la Constitución dice, en la parte que aquí importa, lo siguiente:

"Al Tribunal Electoral le corresponde resolver en forma definitiva e inatacable, en los términos de esta Constitución y según lo disponga la ley, sobre:

I. Las impugnaciones en las elecciones federales de diputados y senadores;

II. Las impugnaciones que se presenten sobre la elección de Presidente de los Estados Unidos Mexicanos que serán resueltas en única instancia por la Sala Superior.

Las salas Superior y regionales del Tribunal sólo podrán declarar la nulidad de una elección por las causales que expresamente se establezcan en las leyes.

La Sala Superior realizará el cómputo final de la elección de Presidente de los Estados Unidos Mexicanos, una vez resueltas las impugnaciones que se hubieren interpuesto sobre la misma, procediendo a formular, en su caso, la declaración de validez de la elección y la de Presidente Electo respecto del candidato que hubiese obtenido el mayor número de votos". 
una elección, como proceso en su conjunto, es violatoria de normas constitucionales.

b) La atribución de las salas del Tribunal Electoral en la norma fundamental, conlleva el garantizar que los comicios se ajusten no solamente a los principios de legalidad sino también a los de constitucionalidad.

c) Las disposiciones legales de orden secundario o de nivel jerárquico inferior a la Constitución, no son la única fuente o vía para regular los supuestos permisivos, prohibitivos, dispositivos o declarativos que rigen las elecciones a cargos de elección popular (sic), de manera tal que se puede decretar la invalidez o la nulidad de una elección por la violación o conculcación a principios constitucionales.

d) Si se presentan casos en los cuales las irregularidades probadas en un proceso electoral son contrarias a una disposición constitucional, ese acto o hecho, al afectar o viciar en forma grave y determinante el proceso comicial atinente, podría conducir a la invalidez de la elección por ser contraria a los principios de la ley fundamental.

e) Tales aspectos se encuentran regulados en la Constitución o en los tratados internacionales de derechos humanos suscritos y ratificados por el Estado mexicano que, por su rango normativo, se traducen en presupuestos o condiciones imprescindibles para la validez de todo acto, resolución, elección o proceso.

f) Si se acredita la violación de distintos principios en la materia electoral que prevé la ley suprema, no se requiere la reiteración en normas secundarias ni la consignación expresa de la consecuencia de nulidad, pues basta con justificar fehacientemente que se han contravenido dichas normas y principios constitucionales de manera generalizada y grave, así como que ello es determinante en la elección, para declarar su invalidez.

\section{Los gastos excesivos de campaña violan la equidad y pueden generar la invalidez}

En el apartado 5.4.1 del considerando octavo de su sentencia, el TEPJF repasa las disposiciones sobre gastos de campaña y sus límites: 
En la generalidad de regulaciones electorales - apunta-, se ha considerado que el tope de gastos en una campaña constituye un límite a las erogaciones de los partidos políticos durante un procedimiento electoral, y tiene por objeto garantizar que en el desarrollo de la contienda prevalezcan condiciones de equidad, en aras de salvaguardar los principios rectores de toda elección democrática, ya que de esta manera se impide que un partido pueda gastar más de lo autorizado por la propia ley, durante la etapa de campaña electoral.

La Sala Superior enlista asimismo las siguientes premisas constitucionales y legales:

- En materia de financiamiento de los partidos políticos, de conformidad con el artículo 41, segundo párrafo, base II, de la carta magna, la ley garantizará que los partidos políticos cuenten de manera equitativa con elementos para llevar a cabo sus actividades; establecerá las reglas a que se sujetarán su financiamiento de los partidos políticos y sus campañas electorales, debiendo asegurar que los recursos públicos prevalezcan sobre los de origen privado; fijará los criterios para determinar los límites a las erogaciones de los partidos políticos en sus campañas electorales; establecerá los montos máximos que tendrán las aportaciones pecuniarias de sus simpatizantes y los procedimientos para el control y vigilancia del origen y uso de todos los recursos con que cuenten, y señalará las sanciones que se deban imponer por el incumplimiento de estas disposiciones.

- El Código Federal de Instituciones y Procedimientos Electorales, en su artículo 77, párrafo 6, prevé que la revisión de los informes que los partidos políticos y las agrupaciones políticas presenten sobre el origen y destino de sus recursos ordinarios y de campaña, según corresponda, así como la práctica de auditorías sobre el manejo de sus recursos y su situación contable y financiera, estará a cargo de la Unidad de Fiscalización de los Recursos de los Partidos Políticos del Instituto Federal Electoral.

- Para el adecuado control de los recursos indicados, en el orden jurídico mexicano está diseñado un sistema de fiscalización cuyo objeto es someter al imperativo de la ley toda actuación relacionada tanto con los ingresos públicos y privados de los partidos políticos, como con los egresos. 
- Así, el derecho de los institutos políticos a recibir financiamiento público para llevar a cabo sus fines conlleva la correlativa obligación de ejercer de manera responsable tales recursos, así como el deber jurídico de comprobar anualmente, de manera transparente y clara, las erogaciones que hayan efectuado.

- La propia Constitución federal y la regulación secundaria establecen condiciones equitativas de la contienda, lo que constituye uno de los elementos fundamentales de una elección democrática, cuyo cumplimiento debe ser imprescindible para que una elección se considere producto del ejercicio popular de la soberanía, en el marco del sistema jurídico-político construido en la Constitución general y en los ordenamientos electorales estatales, siendo un imperativo de orden público, por ende, de obediencia inexcusable e irrenunciable.

- En el Libro Séptimo, Título Primero, del catálogo sustantivo electoral federal, se regulan los regímenes sancionador electoral y disciplinario interno, precisándose los sujetos, conductas motivo de infracción y sanciones, siendo una infracción administrativa expresamente prevista, el exceder los topes de gastos de campaña por parte, entre otros, de los partidos políticos y candidatos.

Posteriormente, en el inciso $B$ de dicho apartado, la Sala Superior efectúa un importante razonamiento sobre el rebase de los topes de gastos de campaña como posible violación asociada a la invalidez de una elección. No lo dice literalmente el TEPJF, pero de su razonamiento puede inferirse clara y evidentemente que una infracción a tales límites transgrede el principio constitucional de equidad y, por tanto, puede llevar a la invalidez de la elección.

He aquí, literalmente, el razonamiento de la Sala Superior:

La fijación de topes de gastos de campaña tiene por objeto salvaguardar las condiciones de equidad que deben prevalecer en una contienda electoral, pues si bien es cierto que el sistema de financiamiento de los partidos políticos en México, considera como uno de los elementos para su distribución, la fuerza electoral que cada partido político haya mostrado en elecciones previas, la experiencia demuestra que hay partidos políticos que, precisamente por sus condiciones económicas, ven restringida su capacidad para ejercer gastos de campaña, a diferencia de otros que de manera holgada pueden disponer de grandes cantidades de recursos, y en 
la práctica, podría llevar a impactar en la penetración de sus propuestas hacia el electorado en forma desmedida, lo que conduce a la necesidad de establecer un límite que atempere esas diferencias consustanciales que tienen los partidos políticos en cuanto a la disposición de recursos económicos, ya que tal tope al gasto de campañas que rige por igual a todos los contendientes en un procedimiento electoral, tiende a materializar un uso racional del dinero destinado a la propaganda electoral lo que implica una aproximación mayor de las propuestas político-electorales a la ciudadanía, favoreciendo un voto consciente, razonado, informado y libre, como la máxima expresión de la soberanía popular.

De esta forma, la violación al límite a las erogaciones de los partidos políticos en una campaña electoral representa una conducta ilícita que puede atentar contra los principios sustanciales de toda elección democrática.

Lo anterior, sirve de base para establecer que la violación al tope de gastos de campaña, puede dar lugar a la afectación de uno de los principios rectores de la materia electoral, principalmente el referente a la equidad.

\section{La demanda de la coalición Movimiento Progresista}

En su demanda (juicio de inconformidad JIN 359/2012) y escritos posteriores, la coalición Movimiento Progresista (PRD-PT-MC) formuló cinco agravios y expuso diferentes hechos que consideró irregularidades graves durante el proceso electoral, todo lo cual - estimó el demandante - vulneró de manera sistemática y generalizada los principios constitucionales rectores de la materia comicial y resultó determinante para el resultado de la elección presidencial. Presentó también los medios de prueba que estimó pertinentes para acreditar su pretensión de anular esa elección.

Para estudiar el fondo de los agravios y conceptos de nulidad que se hicieron valer en el juicio de inconformidad, la Sala Superior del Tribunal Electoral del Poder Judicial de la Federación ${ }^{5}$ (TEPJF) dividió los planteamientos de la parte actora en ocho apartados:

${ }^{5}$ La Sala Superior del TEPJF estaba integrado en 2012 por los magistrados Alejandro Luna Ramos (presidente), María del Carmen Alanís Figueroa, Constancio Carrasco 
1) Adquisición encubierta en radio, televisión y medios impresos.

2) Uso indebido de encuestas como propaganda electoral.

3) Financiamiento encubierto por conducto de Banca Monex, S.A.

4) Conceptos de agravio relacionados con Tiendas Soriana.

5) Gastos excesivos en campaña electoral y aportaciones de empresas mexicanas de carácter mercantil.

6) Intervención de gobiernos (federal y locales).

7) Compra y coacción del voto antes, durante y después de la jornada electoral.

8) Irregularidades ocurridas durante los cómputos distritales.

Ahora me ocuparé de la primera parte del quinto agravio, es decir de los "gastos excesivos en campaña electoral", comenzando con un resumen de la demanda.

El 12 de julio de 2012, la coalición Movimiento Progresista presentó escrito de demanda de juicio de inconformidad, ante el Consejo General del Instituto Federal Electoral, a fin de controvertir la elección de presidente de los Estados Unidos Mexicanos y solicitar la declaración de no validez de esa elección por violación a los principios constitucionales de elecciones auténticas y sufragio libre, y la cancelación del registro de candidato Peña Nieto, por rebase de topes de campaña.

El IFE entregó el 17 de julio la demanda al TEPJF, donde fue turnada a los magistrados Constancio Carrasco Daza, Flavio Galván Rivera y Salvador Olimpo Nava Gomar, integrantes de la Comisión encargada de elaborar el proyecto de calificación jurisdiccional y, en su caso, la declaración de validez y de presidente electo de los Estados Unidos Mexicanos (Comisión Instructora).

En su demanda, la coalición lopezobradorista expuso diversos hechos que, afirmó, vulneraron los principios de objetividad, legalidad, seguridad, imparcialidad, certeza y equidad que rigen la materia electoral, dado el derroche de recursos económicos utilizados por la coalición Compromiso por México. Para acreditar la existencia de estas conductas, la coalición actora ofreció diversas pruebas entre las cuales destacan: escrito de queja presentada contra Peña Nieto por violación al tope de gastos de campaña, así como las respectivas ampliaciones; escrito de queja por actos de violencia en un evento deportivo; oficio

Daza, Flavio Galván Rivera, Manuel González Oropeza, Salvador Olimpo Nava Gomar y Pedro Esteban Penagos López. 
por el cual se solicitó al secretario ejecutivo del IFE copia certificada de las quejas señaladas, el acuerdo 432/2011, por el que fijó el tope de gastos de campaña; un disco compacto relacionado con una entrevista realizada al vicecoordinador de la campaña de la candidata del PAN, Josefina Vázquez Mota.

La coalición quejosa señala en su alegato que el 16 de abril de 2012 la asociación civil Claridad y Participación Ciudadana presentó una queja ante el IFE en contra de la coalición Compromiso por México y su candidato presidencial, por el rebase de topes de gastos de campaña sólo por los gastos relativos a publicidad. La actora añadió que el 24 de abril de 2012 y en otras fechas posteriores (que no precisa), el PAN presentó diversas denuncias ante el IFE en contra de estos mismos por exceso en el gasto de "propaganda estática".

El 26 de abril de 2012, Ricardo Monreal Ávila y los representantes de los partidos integrantes del Movimiento Progresista ante el IFE presentaron queja por la violación al tope de gastos de campaña que atribuyeron a Peña Nieto y solicitaron el otorgamiento de medidas cautelares para hacer cesar la conducta que motivó la denuncia y preservar el ejercicio de equidad. En el escrito respectivo (radicado con el número de expediente Q-UFRPP 22/2012) se aportaron evidencias de que, al 24 de abril de 2012, los denunciados habían erogado como gasto de campaña una cantidad estimada de $\$ 374920338.21$, superior al límite fijado por el IFE: \$336112 084.16.

El 5 de junio de 2012, la coalición actora presentó ante el Consejo General del IFE una ampliación a su queja y solicitó de nuevo medidas cautelares porque la coalición y el candidato denunciados habían erogado como gastos de campaña presidencial, al 2 de junio de 2012, un total de 719.5 millones de pesos en números redondos tan solo por concepto de propaganda y gastos de campaña cuantificables. El 5 de julio de 2012 la coalición Movimiento Progresista interpuso ante el TEPJF un recurso de apelación para impugnar omisiones sobre la admisión, desahogo y sustanciación del primer escrito de queja (SUPRAP-292/2012), el cual fue resuelto el 20 de junio en el sentido de declarar infundados los conceptos de agravio "al dar cuenta de una serie de diligencias de investigación” que se habían llevado a cabo.

El 10 de julio de 2012, los representantes partidistas mencionados, presentaron una segunda ampliación de la queja en cita, solicitando la aprobación de un procedimiento especial sancionador y extraordinario para la revisión de los informes del origen y monto de los ingresos 
que reciban por cualquier modalidad de financiamiento, así como su empleo y aplicación, relativos a los gastos de campaña presidencial.

Según la actora, de la queja y ampliaciones se deducen indicios de que el gasto de campaña de Peña Nieto estimado para el periodo 3-27 de junio, fue de $\$ 1173486884.00$. De ese modo, las cifras del escrito inicial, las del escrito de ampliación y "el presente libelo de incremento", conducen a estimar que la coalición Compromiso por México y su candidato presidencial realizaron gastos de campaña por \$1 892987873.00 , únicamente por concepto de propaganda electoral y actos de campaña "cuantificables". De ahí que - concluye la actora- los denunciados rebasaron el monto del tope de gastos de campaña establecido.

El Movimiento Progresista también argumentó que el 20 de junio de 2012 el representante del PRD ante el IFE presentó una queja por "actos de violencia física y su financiación por militantes y/o personas vinculadas al Partido Revolucionario Institucional y sus candidatos en las elecciones federales y locales en el Estado de México". Estos hechos ocurrieron el 8 de junio en el marco de un partido de futbol en el Estadio Azteca al que se convocó, por medio de las redes sociales, a integrantes del Movimiento "Yo soy \#132" para manifestarse en contra de Peña Nieto, lo cual originó que la estructura del PRI de esa entidad se organizara para contrarrestar esa manifestación. La coalición señala que a ese estadio llegaron 400 camiones que transportaron a 16000 personas, lo cual constituye un acto de campaña por un monto aproximado de 12.7 millones de pesos.

\section{Informe del IFE y argumentos de la coalición tercera interesada}

De acuerdo con la sentencia, en su informe circunstanciado sobre el JIN 359/2012, el IFE (autoridad responsable) reconoció la existencia de diversas quejas relacionadas con el supuesto rebase del tope de gastos de campaña atribuido a Peña Nieto; entre ellas, la Q-UFRPP 15/12 y sus acumuladas Q-UFRPP 16/12, Q-UFRPP 22/12, Q-UFRPP 41/ 12 y Q-UFRPP 78/12; la queja Q-UFRPP 57/12, relacionada con lo ocurrido en el Estadio Azteca el 18 de junio, así como respecto a los procedimientos relacionados con las tarjetas "Premium Platino" y “La Tamaulipeca”, identificados con la clave Q-UFRPP-144/2012 y Q- 
UFRPP-147/2012, respectivamente, en los que también se denunció el posible rebase del tope de gastos de campaña, procedimientos que - señaló la responsable - estaban en sustanciación.

El IFE objetó parte de las documentales ofrecidas por la actora, por ser documentales privadas en las cuales se expresan hechos que no pueden tener valor probatorio sino hasta que se resuelvan los procedimientos administrativos con los que están vinculados, por lo cual, en todo caso - arguyó- son meros indicios de los hechos en ellos expresados.

Con relación al “Acuerdo del Consejo General del Instituto Federal Electoral, identificado con la clave CG432/2011”, que fija el tope de gastos de campaña de la elección presidencial, la responsable la hizo suya, pero la objetó en cuanto al alcance que pretende darle su oferente.

Por su parte, la coalición Compromiso por México (tercera interesada) señaló: la coalición actora omitió aportar pruebas que generen indicios del supuesto rebase de tope de gastos de campaña, pues "presentó estimaciones alejadas de la realidad, producto de su imaginación"; aludió a supuestas aportaciones ilegales por parte de empresas mercantiles, pero omitió presentar elementos convictivos que apoyaran sus manifestaciones; la actora también reclamó la distribución de tarjetas con monederos electrónicos que en realidad confundió con tarjetas de auxilio para la realización de llamadas, "que no tienen a su favor pagos previos ni pueden ser objeto de recargas de dinero".

\section{Valoración de la Sala Superior: los tiempos de la fiscalización}

En su estudio de fondo sobre el rubro de gastos de campaña, la Sala Superior del TEPJF establece sustancialmente lo que sigue:

Del examen de las principales constancias que obran en el expediente de queja, es posible destacar que, por un lado, diversas personas físicas y morales a los que se les requirió información por la Unidad de Fiscalización, han presentado información relacionada con la supuesta contratación de operaciones que derivarían en gastos invertidos en bienes y servicios para la campaña electoral presidencial, que pudieran vincular a la coalición "Compromiso por México", los partidos políticos que la integran o su entonces candidato presidencial. 
Después de detallar la información y documentación que entregó el "responsable de la administración" de la coalición parcial Compromiso por México, el TEPJF señala que la información sobre los gastos de campaña está sujeta "a la investigación que está desarrollando la Unidad de Fiscalización de los Recursos de los Partidos Políticos, del Instituto Federal Electoral, para ser confrontadas, en su caso aclaradas, constatadas, verificadas, cuantificadas y comprobadas por la autoridad fiscalizadora para que, previa elaboración del dictamen consolidado correspondiente", se someta a consideración del Consejo General del IFE para su aprobación.

Sólo en el momento procedimental en que se apruebe - añade el Tribunal-, esa información:

Adquirirá la definitividad necesaria para que los datos ahí asentados, formen parte de la cuantificación en relación con todos los demás gastos de campaña erogados y fiscalizados, que constituye el referente indispensable para ejercer la facultad fiscalizadora, y en su caso sancionadora... respecto de los ingresos y gastos de campaña, relativos a los candidatos a la Presidencia de los Estados Unidos Mexicanos para el proceso electoral federal dos mil once-dos mil doce, y se aprueba la presentación anticipada del dictamen consolidado y proyecto de resolución de la misma elección presidencial.

En una fiscalización ordinaria de los gastos de campaña, el "momento procedimental en que se apruebe" el dictamen consolidado sería en julio de 2013, pero el IFE aprobó en 2012 un procedimiento fiscalizador anticipado que adelanta ese momento a enero de 2011. Es un esfuerzo de la Unidad de Fiscalización que merece reconocimiento pero que resulta insuficiente de cara a su utilidad para la calificación de la elección presidencial, como quedó evidenciado en la sentencia que analizamos.

A continuación, la Sala Superior apunta:

Debe señalarse que en la especie, la actora se abstiene de señalar elementos de prueba específicos para acreditar los hechos constitutivos del supuesto rebase al tope de gastos de campaña, pues básicamente se remite a las constancias que integran los expedientes de queja antes aludidos, con lo cual incumple con la carga probatoria prevista en el artículo 9, párrafo 1 , incisos e) y f), de la ley adjetiva electoral federal sin que esta Sala Supe- 
rior pueda llevar a cabo pesquisa alguna para acreditar lo aseverado por la enjuiciante.

(Los redactores de la sentencia no explican puntualmente el porqué la Sala Superior no puede realizar "pesquisa alguna"6).

Lo anterior provoca que, al no haber sido aportados elementos probatorios idóneos en el expediente del juicio de inconformidad que se resuelve, a fin de acreditar los hechos aducidos, existe imposibilidad jurídica para tenerlos por demostrados.

Tal conclusión se sustenta en que, como quedó explicado al aludir a las reglas de fiscalización, para verificar los gastos de los partidos políticos existen circunstancias técnicas que precisan de un conocimiento especializado, el respeto de los plazos legales y las formalidades esenciales del procedimiento de investigación para que la revisión y en su caso, la investigación sea eficaz.

Así se corrobora cuando se tiene presente que se trata de una actividad técnica, porque deriva de un procedimiento de fiscalización, auditoría y verificación, en el que hay revisiones sobre el cumplimiento de las reglas de contabilidad, como es la captación, clasificación, valuación y registro contable de ingresos, gastos, adquisición de bienes y documentación comprobatoria; contabilidad patrimonial base acumulada; estados financieros; inventarios de existencia de adquisición de materiales, propaganda electoral y utilitaria, así como de activo fijo (artículos 81 del Cofipe y 20 del Reglamento de Fiscalización respectivo).

Esto significa que se trata de una actividad que sólo puede arrojar hechos probados en cuanto a la determinación exacta de gastos de campaña hasta que se apruebe el dictamen consolidado y proyecto de resolución, el cual, atendiendo al principio de definitividad, ya sea un acto concluido, y esas condiciones, no hay elementos que generen plena convicción respecto a las erogaciones definitivas por concepto de gastos de campaña de la elección presidencial, precisamente porque las actuaciones del procedimiento respectivo están inconclusas y los partidos integrantes de la coalición Compromiso por México, como todos los demás, no han entregado su informe final de gastos de campaña (cuyo plazo vence hasta el 8 de octubre de 2012), conforme al calendario aprobado en el Acuerdo número CG301/2012 por el Consejo General del Instituto Federal Electoral.

${ }^{6}$ La definición de la palabra "pesquisa" es, según el Diccionario de la Real Academia Española, la siguiente: Pesquisa. 1. f. Información o indagación que se hace de algo para averiguar la realidad de ello o sus circunstancias. 
Por las mismas razones, tampoco es dable tener por acreditado el rebase del tope de gastos de campaña, con el expediente de queja identificado con la clave Q-UFRPP 40/2012, el cual como se precisó, no está acumulado al expediente de queja Q-UFRPP 15/2012.

Este último asunto alude a la denuncia presentada el 4 de abril de 2012 por el Partido Acción Nacional ante el Consejo Distrital 03 del IFE en Quintana Roo, en contra del PRI y de Peña Nieto, por la presunta contravención del marco jurídico vigente en materia de propaganda en equipamiento urbano, la cual, después de diversas actuaciones y resoluciones, se remitió a la Unidad de Fiscalización del IFE para investigar los hechos denunciados pero con relación al rebase al límite de erogaciones por concepto de campaña.

Luego de referirse a la argumentación exculpatoria al PRI y su aliado el Partido Verde, el Tribunal señala (se respetan la sintaxis y puntuación de la sentencia):

De lo expuesto se advierte que la Unidad de Fiscalización de los Recursos de los Partidos Políticos ha llevado a cabo diversas actuaciones de investigación, a fin de estar en posibilidad de resolver la queja Q-UFRPP 40/12 y acumuladas, sin embargo el procedimiento no ha concluido, portanto, delos datos parciales que se obtienen lo que se puede tener por acreditado es que se presentó una denuncia relacionada con el posible rebase al tope de gastos de campaña, y que se está llevando a cabo diversas actuaciones de investigación, sin embargo, no es conforme a Derecho tener por acreditados los hechos que fueron motivo de denuncia, lo anterior a fin de garantizar el principio de debido proceso y en atención a la garantía de audiencia establecida por el artículo 14 constitucional consiste en otorgar al gobernado la oportunidad de defensa previamente al acto privativo y su debido respeto impone a las autoridades, entre otras obligaciones, la de que en el juicio que se siga se cumplan las formalidades esenciales del procedimiento.

Conforme a lo anterior, si bien los procedimientos de fiscalización de los recursos de los partidos políticos no son juicios, ha sido criterio de este órgano jurisdiccional que en ellos se deben respetar las garantías de defensa, que, de manera genérica, se traducen en los siguientes requisitos: 1) La notificación del inicio del procedimiento y sus consecuencias; 2) La oportunidad de ofrecer y desahogar las pruebas en que se finque la defensa; 3) La oportunidad de alegar; y 4) El dictado de una resolución que dirima las cuestiones debatidas. De no respetarse estos requisitos, se dejaría de cumplir con el fin de la garantía de audiencia. 
En tales condiciones, se arriba a la conclusión de que en este caso, tampoco hay elementos que generen plena convicción respecto a las erogaciones definitivas por concepto de gastos de campaña de la elección presidencial, precisamente porque las actuaciones del procedimiento respectivo están inconclusas y los partidos integrantes de la Coalición "Compromiso por México" [como todos los demás, no han entregado su informe final de gastos de campaña].

En ese tenor, al no tenerse plena certeza sobre los hechos irregulares aducidos por la coalición Movimiento Progresista actora en el presente juicio, en tanto que la actora no aportó pruebas suficientes para tal efecto, resultan infundados los motivos de nulidad relativos a que derivado de las quejas citadas, quedó acreditado el rebase al tope de gastos de la campaña mencionada.

Hasta aquí la argumentación de la Sala Superior.

Es imperativo formular aquí una pregunta: ¿cómo podría haberse aportado "pruebas suficientes" para acreditar el rebase del tope de gastos de campaña si los "elementos que generen plena convicción” no pueden existir sino hasta cuando concluya el procedimiento de fiscalización? Es claro que, con este criterio, el exceso en la campaña proselitista, que rompe la equidad en la contienda y vulnera por tanto un principio constitucional, nunca podrá incidir en la calificación de la elección presidencial... a menos que la máxima autoridad en la materia se decida a "garantizar que los comicios se ajusten no solamente a los principios de legalidad sino también a los de constitucionalidad", como se establece en la propia sentencia. ${ }^{7}$ Para ello, la Sala Superior tendría que haber tomado una serie de decisiones - en especial ordenar un procedimiento fiscalizador extraordinario- que no tomó y, por tanto, dejó de ofrecer certeza respecto a la probable violación de principios constitucionales en el proceso electoral 2011-2012.

7 El fragmento respectivo (p. 57 de la sentencia) dice textualmente: “... la atribución que tienen asignadas las salas del Tribunal Electoral en la norma fundamental, conlleva el garantizar que los comicios se ajusten no solamente a los principios de legalidad sino también a los de constitucionalidad, de modo tal que cuando se realice un estudio para constatar que el proceso electoral cumplió con los principios constitucionales, podrá determinar si la elección es válida o si la misma carece de validez, para los efectos de mantenerla subsistente o no respecto de la renovación de los cargos públicos”. 


\section{VII. ¿Es posible cancelar el registro por rebasar los topes de campaña?}

En seguida, la Sala Superior aborda a medias un asunto polémico al que sólo alude implícitamente: ¿procede la cancelación del registro de un candidato por rebasar los topes de gastos de campaña? Durante el proceso electoral 2012 y ante el gran despliegue publicitario del candidato priista, proliferaron las opiniones favorables, incluso de especialistas, sobre tal cancelación, mientras otros opinaban que no era procedente. La confusión deriva de la sanción prevista en el artículo $214.4^{8}$ del Cofipe, el cual señala que los precandidatos que rebasen el tope de precampaña perderán "la candidatura que hayan obtenido" y en este caso los partidos que los hayan postulado podrán sustituirlos. Extrapolar esa sanción a los candidatos que obtengan una mayoría de votos parece sensato, pero el Cofipe no lo considera así y sólo fija sanciones económicas a candidatos y partidos que incurran en esa irregularidad.

Abona a la confusión el artículo $354^{9}$ del Cofipe que, al enlistar en su inciso $c$ las sanciones por "infracciones señaladas en los artículos anteriores" (entre las cuales figura el rebase del tope de gastos de campaña o de precampaña), incluye la pérdida del registro, si bien es claro que se refiere exclusivamente al "precandidato infractor"

Yo creo que no es procedente la cancelación del registro de los candidatos que rebasen el tope de gastos de campaña, lo cual se ase-

8 El numeral 4 del artículo 214 del Cofipe señala: "Los precandidatos que rebasen el tope de gastos de precampaña establecido por el Consejo General serán sancionados con la cancelación de su registro o, en su caso, con la pérdida de la candidatura que hayan obtenido. En el último supuesto, los partidos conservan el derecho de realizar las sustituciones que procedan".

9 Artículo 354 del Cofipe:

Las infracciones señaladas en los artículos anteriores serán sancionadas conforme a lo siguiente:...

c) Respecto de los aspirantes, precandidatos o candidatos a cargos de elección popular:

III. Con la pérdida del derecho del precandidato infractor a ser registrado como candidato, o en su caso, si ya está hecho el registro, con la cancelación del mismo. Cuando las infracciones cometidas por aspirantes o precandidatos a cargos de elección popular, cuando sean imputables exclusivamente a aquéllos, no procederá sanción alguna en contra del partido político de que se trate. Cuando el precandidato resulte electo en el proceso interno, el partido político no podrá registrarlo como candidato. 
mejaría en cierta forma a la invalidez de la elección cuando se trata de quien obtiene la mayoría de votos, pero el TEPJF no lo precisa suficientemente en la sentencia. La Sala Superior entreabre la puerta a esa posibilidad, pero luego parece cerrarla al citar la única sanción prevista en el Cofipe para tal rebase.

La Sala Superior aborda el asunto en estos términos:

Derivado de lo anterior, tampoco procede acoger la pretensión de la actora consistente en que al haberse actualizado el rebase del tope de gastos de campaña, procedería la cancelación del registro del candidato presidencial postulado por la coalición Compromiso por México, dado que por un lado, no se actualizó el presupuesto, que en concepto de la actora, trae como consecuencia tal cancelación.

En una situación ordinaria, tratándose del rebase de topes de gastos de campaña, en el Código Federal de Instituciones y Procedimientos Electorales, se establece que la sanción será de un tanto igual al del monto ejercido en exceso, y que, en caso de reincidencia, la sanción podrá ser hasta el doble de lo anterior, en términos de artículo 354, párrafo 1, inciso a), fracción II, del Código Federal de Instituciones y Procedimientos Electorales.

En una situación extraordinaria, ante la existencia del rebase del tope de gastos de campaña que se acreditara fehacientemente, este órgano jurisdiccional podría analizar la posible existencia de una violación a los principios constitucionales y proceder como correspondiera.

De esta manera, la consecuencia jurídica que pretende la actora, en el caso, no resulta procedente.

En síntesis, el TEPJF procedería "como correspondiera" - se entiende que inclusive invalidando la elección-, pero por violación a principios constitucionales, lo cual es diferente a cancelar el registro del candidato.

\section{La rechazada "excitativa de justicia" del Movimiento Progresista}

En la parte final de su valoración sobre los gastos de campaña, la Sala Superior ratificó su rechazo a las pretensiones del Movimiento Progresista a requerir a la Unidad de Fiscalización del IFE que resolviera 
diversas quejas, pero no aludió expresamente a otra importante solicitud de esa coalición, sobre un procedimiento extraordinario de fiscalización a los gastos de campaña de Peña Nieto. Lo que sí hizo el Tribunal fue remitir a su resolución incidental recaída sobre la solicitud de una "excitativa de justicia" por parte de la coalición actora, la cual fue rechazada el 1o. de agosto de 2012.

La Sala Superior argumentó sustancialmente lo que sigue:

Finalmente, la coalición actora aduce que este órgano jurisdiccional debe requerir a la Unidad de Fiscalización de los Recursos de los Partidos Políticos del IFE, a efecto de que emita de inmediato la resolución de la queja en la que se denunciaron como hechos constitutivos de infracción los relacionados con la tarjeta denominada "PREMIUM PLATINO", así como las identificadas con el número de expediente Q-UFRPP 16/12, QUFRPP 40/12 y Q-UFRPP 41/12 antes de que se emita la calificación de la elección respectiva, a fin de que se tenga pleno conocimiento de las sanciones impuestas a los responsables de las irregularidades cometidas. Similar circunstancia expresa respecto de la queja relacionada con los hechos ocurridos en el "Estadio Azteca" el 18 de junio de 2012.

Ahora bien, a juicio de esta Sala Superior, tales manifestaciones ya fueron objeto de resolución por parte de esta Sala Superior, pues el 23 de julio de 2012, la coalición Movimiento Progresista presentó un escrito por el que 'se solicita proveído de trámite para resolución de quejas (excitativa de justicia), a fin de que esta Sala Superior proveyera lo necesario para la tramitación y resolución de diversos procedimientos sancionadores. El 1 de agosto de 2012, esta Sala Superior resolvió los autos de la cuestión incidental relativa a esa petición presentada por la actora, tanto en el escrito de demanda inicial como en diversas promociones dirigidas al juicio de inconformidad identificado con la clave SUP-JIN-359/2012.

En tal resolución incidental se consideró que la coalición Movimiento Progresista, en esencia, tenía una pretensión a partir de dos finalidades: a) Que la Sala Superior dictara un acuerdo de 'excitativa de justicia' al Consejo General y la Unidad de Fiscalización del IFE, para que resolvieran oportunamente determinados procedimientos administrativos sancionadores ordinarios, especiales y en materia de quejas sobre financiamiento y gasto de los partidos políticos, antes de que se decidiera el juicio de inconformidad por nulidad de la elección presidencial, y b) Una resolución que subsanara lo que la misma coalición actora denominó errores y omisiones de trámite y sustanciación de distintos procedimientos que están iden- 


\begin{abstract}
tificados con diversos procedimientos administrativos sancionadores ordinarios, especiales y en materia de quejas sobre financiamiento y gasto.

En el caso, esta Sala Superior consideró improcedente la petición de excitativa de justicia toda vez que no existe una relación de jerarquía orgánica entre la autoridad administrativa y la jurisdiccional. En tales condiciones, lo aducido por la coalición actora (en la demanda inicial del juicio de inconformidad) ya fue materia de pronunciamiento por esta Sala Superior.
\end{abstract}

Como se ve, en su valoración el tribunal no menciona expresamente la solicitud de la coalición actora sobre la realización de un procedimiento extraordinario de fiscalización, que figura en la demanda inicial y en promociones posteriores. Importa por ello citar que en su sentencia (p. 16), la Sala Superior señala lo siguiente sobre la rechazada "excitativa":

3. Resolución incidental. El primero de agosto del año en curso, previa propuesta de la Comisión instructora, la Sala Superior dictó resolución incidental relativa a la solicitud de "excitativa de justicia", declarando (que) no ha lugar a acordar favorablemente las peticiones formuladas por la coalición "Movimiento Progresista". Lo anterior, toda vez que, por un lado, no le corresponde a la Sala Superior, sino al Consejo General del Instituto Federal Electoral, resolver sobre la apertura de un procedimiento extraordinario de fiscalización, en el ámbito de sus atribuciones constitucional y legalmente previstas, y por el otro, no está prevista en el ámbito electoral federal el remedio procesal solicitado y no existe una relación de jerarquía orgánica entre la autoridad administrativa y la jurisdiccional, por lo que, si bien, los procedimientos administrativos sobre los cuales se solicita la medida pueden ser revisados por esta autoridad jurisdiccional, ello debe ser conforme al sistema de medios de impugnación previstos en la Constitución y en la Ley, del cual no forma parte la excitativa de justicia.

Esa resolución incidental, que habría de retomarse en la sentencia que analizamos, constituye, desde mi perspectiva, la parte más lamentable de la actuación de la Sala Superior del TEPJF porque implica una abdicación a su papel de garante de la Constitución. Lejos del garantismo, atrapado por el formalismo, el tribunal se automutila y se ve sin atribuciones para ordenarle al IFE lo único que pudo arrojar luz 
institucional sobre lo que para muchos - yo entre ellos - fue muy evidente: que en la campaña de la coalición Compromiso por México (integrado por PRI y PVEM) y su candidato Peña Nieto se rebasó por mucho el tope de gastos de campaña fijado en 336 millones de pesos para los comicios presidenciales.

En efecto, lo único que pudo arrojar luz institucional sobre el presumible rebase era un procedimiento extraordinario de fiscalización de las finanzas, en particular las de campaña, de la coalición de Peña Nieto. El fundamento legal para ese procedimiento está en el artículo $85^{10}$ del Cofipe, pero el TEPJF consideró ese 1o. de agosto, que:

No procede acordar favorablemente la petición de la actora, en el sentido de que esta Sala Superior ordene al Consejo General del mencionado Instituto que, a su vez, instruya a la Unidad de Fiscalización para abrir un procedimiento extraordinario de fiscalización, porque esa determinación corresponde emitirla solamente al citado órgano supremo de dirección en materia electoral federal, en el ámbito de sus atribuciones constitucional y legalmente previstas. ${ }^{11}$

De ese modo, los magistrados que han revocado mil y una resoluciones de la autoridad administrativa electoral, que han reenviado una y otra vez al Consejo General asuntos que pudieron resolver si asumían plenitud de jurisdicción, en un exceso que llevó a Carpizo a pensar en una "fuente de inestabilidad del sistema electoral", ${ }^{12}$ esos magistrados no hallaron "una potestad constitucional y legal conferida a esta Sala Superior" para ordenar un procedimiento extraordinario de fiscalización.

Hay opiniones de especialistas en el sentido de que el IFE pudo contribuir por sí mismo a la determinación de un eventual rebase de la coalición Compromiso por México. Uno de esos especialistas, Rogelio

10 Artículo 85 del Cofipe:

1. En casos de excepción, y previo acuerdo del Consejo General, la Unidad podrá abrir procesos extraordinarios de fiscalización con plazos diferentes a los establecidos en el artículo anterior. En todo caso, los procesos extraordinarios deberán quedar concluidos en un plazo máximo de seis meses, salvo que el Consejo General autorice, por causa justificada, la ampliación del plazo. Los acuerdos del Consejo a que se refiere este artículo podrán ser impugnados ante el Tribunal Electoral.

11 Incidente sobre solicitud de "Excitativa de justicia”. Expediente: SUP-JIN-359/2012

12 Carpizo, Jorge, “Prólogo", en Córdova, Lorenzo, y Salazar, Pedro (coords.), Democracia sin garantes. Las autoridades vs. La reforma electoral, México, UNAM, Instituto de Investigaciones Jurídicas, 2009, p. XV. 
Muñiz Toledo, sostiene que, aceptando la falta de competencia alegada por el tribunal:

De la mencionada resolución incidental del 1 de agosto del TEPJF se desprende que no había impedimento para que el IFE abriera el procedimiento extraordinario de fiscalización y, en caso de que esta determinación fuera impugnada, se hubiera abierto la vía legal para que la Sala Superior se pronunciara sobre la procedencia o no del procedimiento extraordinario aprobado por el IFE y, entonces sí, la responsabilidad de actuar o no con un criterio garantista y protector de la constitucionalidad hubiera recaído en el tribunal. Como no le tomó la palabra al tribunal, el IFE comparte la responsabilidad en este rubro. Si el IFE hubiera decidido ejercer sus atribuciones al límite y cumplir con su papel de garante de la constitucionalidad de la elección — que también lo es-, los márgenes para que el tribunal hubiera podido aplazar su resolución se hubiesen ampliado - dentro de un plazo razonable entre septiembre y noviembre-, en espera de las conclusiones de las investigaciones que el IFE no quiso realizar. ${ }^{13}$

Es interesante este razonamiento, pero en el supuesto que se plantea, me parece difícil que los magistrados de la Sala Superior hubieran actuado de una forma diferente a como lo hicieron.

Ahora bien, ¿y si la Unidad de Fiscalización prueba en su momento que la campaña de Peña Nieto rebasó con mucho el tope de gastos de campaña de 336 millones de pesos?

Dejemos que responda uno de los magistrados, Flavio Galván Rivera:

¿Habrá hechos que se hayan cometido ilícitamente? Puede ser. Serán las autoridades hacendarias, las autoridades administrativas electorales, las autoridades de procuración de justicia o a la que corresponda, las que, en su momento, también arriben a sus respectivas conclusiones. En materia electoral no están demostrados los hechos y por tanto no está demostrada la ilegalidad de la elección presidencial. ${ }^{14}$

${ }_{13}$ Muñiz Toledo, Rogelio, "Elección presidencial 2012: la fiscalización extraordinaria que no se realizó", documento de trabajo.

14 Versión estenográfica de la sesión pública de resolución de la Sala Superior del Tribunal Electoral del Poder Judicial de la Federación, efectuada el 30 de agosto de 2012. 
Es pertinente preguntarse también si, tras de la sentencia que analizamos, está demostrada la legalidad y, sobre todo, la constitucionalidad de la elección presidencial de 2012. Lo que sí es cierto es que los hechos denunciados no fueron probados, como también lo es que el tribunal no hizo mucho para perfeccionar las pruebas e indicios que se le presentaron y esto pone en duda su carácter de garante de la Constitución. El jurista Jaime Cárdenas, autor de una parte de la demanda de juicio de inconformidad, ha sostenido:

Desde la perspectiva del Tribunal Electoral, su papel de garante de la Constitución es pasivo y no proactivo, es decir, poco garante o garante a medias de la Constitución. Le pide a las partes las pruebas para decir el derecho, como cualquier tribunal de legalidad, cuando por su carácter de tribunal constitucional su función primordial era hacer que la Constitución fuese una realidad y para ello debía echar mano de todos los elementos a su alcance a fin de esclarecer si hubo o no las violaciones a la Constitución que señalaba la coalición Movimiento Progresista. ${ }^{15}$

Ciertamente, los denunciantes no aportaron las pruebas que pedían los magistrados. Y no las aportaron porque no las tenían, porque no podían tenerlas. Pero sí podían tenerlas la Secretaría de Hacienda, la Comisión Nacional Bancaria, el Servicio de Administración Tributaria (SAT), la PGR por conducto de la FEPADE y la Unidad de Fiscalización del IFE, que tiene atribuciones para superar los secretos fiduciario, bancario y fiscal.

¿Cómo se prueba que uno o más partidos rebasaron el tope de gastos de campaña? Se prueba con auditorías, con facturas, con informes de proveedores, con trabajo de campo, con seguimiento a la propagada y a los mítines...

¿Es racional suponer que un partido o coalición puede obtener esas facturas, esos informes... o realizar los trabajos de campo? ¿Con qué autoridad puede un partido obtener esas pruebas? Es obvio que los partidos sólo pueden obtener indicios. Esos indicios fueron los que presentó la coalición actora, pero es también obvio que a la autoridad jurisdiccional le correspondía perfeccionar esas pruebas. Y eso fue lo que no hizo el TEPJF.

${ }^{15}$ Cárdenas Gracia, Jaime, "El tribunal que se olvidó de la Constitución”, Emeequis, 289, 9 de septiembre de 2012, p. 43. 
Si la coalición actora hubiera reunido esas pruebas, taumaturgia de por medio, ni aun así hubiera convencido al tribunal. Como se transcribió anteriormente, la Sala Superior considera que sólo puede haber "hechos probados en cuanto a la determinación exacta de gastos de campaña hasta que se apruebe el dictamen consolidado y proyecto de resolución". Y como esto ocurrirá —en este caso- en enero de 2013 y la sentencia se emitió el 30 de agosto de 2012, no hay manera de probar un exceso en tales egresos. De ese modo el tribunal extendió un manto protector a la coalición acusada y le dio un renovado impulso al uso de dinero ilegal en las campañas. Con esos vientos en la popa, continuará su navegación vigorosa y perversa la práctica de rebasar los topes de gastos de campaña bajo la lógica de que el puesto obtenido ilegalmente se conserva a pesar de que se transgredan la Constitución y el Cofipe y aunque se tenga que pagar una sanción económica.

Con su sentencia, adicionalmente, la Sala Superior incumplió uno de los principios constitucionales en materia electoral: la certeza. ¿Cómo puede haber certeza si incluso los magistrados vislumbran hechos ilícitos que con posterioridad sean determinados por otras autoridades?

Se ha discutido si, al no estar previsto como causal de nulidad, el rebase del tope de gastos de campaña puede motivar la invalidez de la elección presidencial. Es evidente que sí - y así lo señala implícitamente la sentencia que analizamos- porque con esa infracción se violenta el principio constitucional de equidad, pero no sólo ésta. También porque tal exceso fácilmente puede asociarse a la transgresión de al menos uno de los otros principios considerados por la Constitución como imprescindibles para que una elección sea libre y auténtica: la prevalencia de los recursos públicos sobre los de origen privado (artículo 41, párrafo segundo, base II, de la Constitución).

En tales circunstancias resulta evidente que el TEPJF incumplió, lamentablemente, con su deber de garantizar que los comicios se ajusten no solamente a los principios de legalidad sino también a los de constitucionalidad.

\section{Conclusiones}

De cara a las campañas electorales y a las ventajas que se derivan de disponer de mayor financiamiento, el legislador creó la figura del tope 
de gastos de campaña, si bien resulta difícil encontrar una elección importante en que tales límites se respeten. Los contendientes no han tenido incentivos para respetarlos sino, al contrario, estímulos para sobrepasarlos, pues las autoridades electorales, tanto administrativas como jurisdiccionales, se han limitado a sancionar sólo con penas pecuniarias los rebases, aun cuando ese tipo de excesos esté considerado como causal de nulidad en las legislaciones estatales.

Con estos antecedentes, la Sala Superior del TEPJF desestimó los argumentos, pruebas e indicios que presentó la coalición Movimiento Progresista (PRD, PT y MC) sobre lo que consideró un rebase del tope de gastos de campaña por la coalición Compromiso por México (PRI y PVEM) que postuló a Enrique Peña Nieto, a quien el tribunal declaró presidente electo.

La profusa propaganda peñista, los gastos en mítines, los indicios de triangulación financiera, los casos de compra de votos, la vasta propaganda utilitaria generaron la percepción de que la campaña priista rebasó por mucho el límite de 336 millones de pesos fijado por el IFE para la campaña presidencial. La Sala Superior del TEPJF consideró que la coalición actora debió probar tal rebase, aun cuando un partido político está imposibilitado para ello, porque las pruebas —que sí poseen o pueden poseer otra autoridades- están física y legalmente fuera de su alcance. El mismo tribunal, por conducto de uno de sus magistrados, estimó que podría haber hechos ilícitos en el proceso electoral, pero que éstos correspondían a otras autoridades. La Sala Superior señaló que, debido a los tiempos y plazos de la fiscalización a cargo de la unidad técnica del IFE, una transgresión a los topes sólo podría conocerse al final de los procedimientos de fiscalización, pero rechazó ordenar un procedimiento extraordinario de fiscalización como el previsto en el artículo 85 del Cofipe y de ese modo dejó de conferir certeza a su sentencia.

Quedó en duda también si en el proceso electoral fueron violados principios constitucionales como la equidad, la legalidad, la certeza y la prevalencia del dinero público sobre el privado. Con los criterios aplicados en 2012, el TEPJF dejó de ejercer las atribuciones inherentes a su carácter de tribunal constitucional en su materia. En cambio, el tribunal ratificó un importante criterio: pese a lo dispuesto en el artículo 99 constitucional, en el sentido de que sólo podrá declarar la nulidad de una elección por las causas expresamente incluidas en la ley, la Sala Superior: 
puede válidamente declarar la invalidez o nulidad de la elección de Presidente de los Estados Unidos Mexicanos por conculcación de determinados principios constitucionales o por la vulneración de ciertos valores fundamentales e indispensables para considerar una elección como libre, auténtica y democrática.

El juicio de inconformidad promovido por el Movimiento Progresista y la sentencia del TEPJF también evidenciaron la necesidad de emprender una nueva serie de reformas constitucionales y legales en materia electoral, como las que se enuncian a continuación.

\section{Propuestas}

Primera. Es inocultable la inequidad actual (2012) en la distribución del financiamiento público a los partidos políticos, por cuanto el más votado recibió ese año casi cinco veces más que el menos votado. No se discute que el partido con más sufragios obtenga también más dinero, pero ¿debe ser tan abismal la diferencia?

En diversos foros y textos he propuesto un nuevo esquema de financiamiento que me parece adecuado para abordar la necesaria reducción de los recursos partidarios y que consiste centralmente en su vinculación con los porcentajes de participación total de los ciudadanos en las elecciones. Explico esta propuesta:

a) La forma de determinar la bolsa se mantiene (65\% del salario mínimo multiplicado por el número de ciudadanos inscritos en el padrón).

b) El monto que resulte de esa bolsa no se distribuye totalmente, sino sólo en un porcentaje igual al de la participación del electorado en la elección anterior. Por ejemplo, de los 5142 millones previstos para 2012, el monto por repartir habría sido de 2313 millones (45\% del total, porcentaje equivalente a la votación del 5 de julio de 2009).

De ese modo habría una disminución en el financiamiento público y, algo no menos importante, se incentivaría a los partidos a esforzarse por abatir el abstencionismo y desmotivar el voto nulo, algo que ac- 
tualmente no parece preocuparles. ¿Se trata de empobrecer a los partidos? De ninguna manera, pero sí de adecuarlos a la situación económica del país y de eliminar recursos que frecuentemente sirven para la compra e inducción del voto. No es racional ni ética la existencia de partidos ricos en un país que, en su inmensa mayoría, no lo es.

Es aconsejable, asimismo, retirar de la Constitución las disposiciones puntuales sobre el financiamiento de los partidos políticos, habida cuenta de que ningún otro ente goza de ese injustificado privilegio.

Segunda. Aun cuando el exceder los límites de gastos de campaña puede considerarse causal de nulidad de una elección porque viola el principio constitucional de equidad, es pertinente agregar ese carácter en la Constitución o en la Ley General del Sistema de Medios de Impugnación en Materia Electoral.

Con frecuencia el TEPJF le ha negado determinancia a tales rebases cuando están considerados como causales de nulidad en las legislaciones locales, de suerte que para evitar esa discrecionalidad convendrá fijar un porcentaje de tolerancia - de 5\%, por ejemplo- a partir del cual se considere necesariamente determinante el exceso. Y para cerrar el círculo, es pertinente disponer expresamente que en los rebases del límite de gastos de campaña, no se aceptarán como justificación los errores contables reales o supuestos.

Tercera. Los plazos vigentes para la fiscalización de las finanzas de los partidos políticos, en particular los gastos de campaña, son absurdos porque llevan a que el respectivo dictamen consolidado sea sometido a consideración del Consejo General del IFE un año después de la elección, lo cual dificulta que una eventual transgresión sea incluida de manera natural en los juicios de inconformidad que se presenten ante el TEPJF.

Una manera de resolver este problema es que, por una parte, se acorten los plazos de fiscalización y se evite su actual carácter ex post $y$, por otro, se alarguen los plazos, hasta fines de octubre, por ejemplo, para que el TEPJF resuelva los recursos que controviertan la elección presidencial. 